www.jmscr.igmpublication.org

Impact Factor (SJIF): 6.379

Index Copernicus Value: 71.58

ISSN (e)-2347-176x ISSN (p) 2455-0450

crossref DOI:_https://dx.doi.org/10.18535/jmscr/v6i2.03

Journal Of Medical Science And Clinical Research

\title{
Clinical Presentation and Spectrum of Involvement of Rotator Cuff Tendon and Its Associated Pathologies
}

\author{
Authors \\ Dr Vishwas Chakra $\mathbf{V}^{\mathbf{1}}$, Dr Mukul Chotrani \\ ${ }^{1}$ Assistant Professor, ${ }^{2}$ Senior Resident \\ Department of Radiodiagnosis, Ananta Institute of Medical Sciences \& Research Centre
}

\begin{abstract}
Background: Rotator cuff tendon tear is very common problem and its frequency is found to be increasing. It is characterized by immense pain, weakness, stiffness which is the outcome of tendon tears. It's also known as tendinopathy. Various data's are available on RCT which can help to understand the tendinopathies and associated pathologies.

Aim: Purpose of this descriptive study is to study the Clinical presentation and spectrum of involvement of rotator cuff tendon and its associated pathologies

Material and Method: Patients referred to the Department of Radio diagnosis, Rural medical college, Pravara Institute of Medical Sciences, Loni, for MRI shoulder with suspected shoulder pathology were examined. 70 patients aged above 18 years with Rotator cuff lesions were detected on magnetic resonance imaging of the shoulder joint and were selected for the study.

Result: The most frequent presenting complaint in patients with rotator cuff disease was pain in $57 \%$ cases followed by stiffness resulting in reduced range of movement across the shoulder joint. The most commonly affected tendon is the supraspinatus tendon in $81 \%$ cases. The least frequently affected tendon being the teres minor.

Conclusion: Rotator cuff disorders occur both in male and female with no gender predisposition. It is a common contributing factor of shoulder pain. A detailed knowledge on the same can help to reduce the discomfort caused.
\end{abstract}

Keywords: Rotatory cuff, tendon, tear, shoulder joint, pain.

\section{Introduction}

The shoulder joint is multiaxial with a wide range of movements provided at the cost of skeletal stability. Shoulder joint pain is considered to be the third most common skeletal pain. ${ }^{1}$ Rotator cuff tendons impingement or subdeltoid bursa, bicipital tendonitis, frozen shoulder, and glenohumeral, and acromioclavicular arthritis are some of the most frequently diagnosed shoulder problems. ${ }^{2}$ Rotator cuff tears are more common and has a prevalence rate of $26 \%$. $^{3}$ rotatory cuff lesions are often associated with severe pain, stiffness, functional disability which all together leads to a compromised life quality and patients have to depend on others for their basic needs. ${ }^{4,5}$ According to the data available the expected reason for the tear of rotatory cuffs could be due to chronic degeneration. The rotator cuff tear can be of either partial thickness or full thickness. ${ }^{6,7}$ Milgrom $\mathrm{C}$ et al recommended that hand 
dominance, occupation and leisure activities have a limited influence on the timing of onset and rate of progression of mature atraumatic tendon degeneration. ${ }^{8}$ However the location and size of the rotator tear can have great impact on diagnosis and treatment outcome. ${ }^{9}$ Diagnosis of tendinopathy has a very important role to play only with the accurate diagnosis patients suffering can be minimized. There comes the role of magnetic resonance imaging. MRI has good spatial resolution for assessment of soft tissue, to identify tendon edema \& tear in the muscle cuff. Rotator cuff lesions are common yet complex in nature which can have a severe impact on patient's life so, the purpose of present study was to study the clinical presentation and spectrum of involvement of rotatory cuff tendon and its associated pathologies.

\section{Material and Method}

70 patients aged between above 18 attending Department of Radiodiagnosis, Rural medical college, Pravara Institute of Medical Sciences, Loni, for MRI shoulder with suspected shoulder pathology were included in the study. Ethical clearance was obtained. Patients were explained regarding the procedures to be performed and treatment. Written informed consent was obtained from patients/guardians.

\section{Inclusion criteria}

1) Patients above 18 years of age,

2) Those with possible shoulder pathology, detected as rotator cuff tear.

3) Those willing to participate in the study

\section{Exclusion criteria}

1) Postoperative patients.

2) Known case of rotator cuff lesions on treatment.

3) Patients with contraindicated MRI

4) Medically compromised patients

Complete clinical and physical examination was carried out for all the patients. All the patients with the complaint of shoulder pain were subjected to MRI scan using 1.5 T MRI scanners. The patients were positioned in supine position with the head directed toward the scanner bore. The patient's arms rested to the side of the body and should not be placed on the abdomen to avoid transmission of respiratory motion. Patients were than examined for full thickness and partial thickness tear. Spectrum involvement and associated pathologies were recorded. Out of 70 patients included in study 38 were males and 32 females. Clinical signs reported by the patients were recorded.

\section{Statistical Analysis}

Data was collected each variable was analyzed and A $p$-value $<0.05$ was considered statistically significant. Data was analyzed by specific statistical software (IBMSPSS V10 STATISTICS, IBM, ARMONK, USA).

\section{Result}

The sample size for the current study was a total of 70 patients aged above 18 years. Out of 70 patients $38(55 \%)$ male patients and $32(45 \%)$ female patients had rotator cuff disease in this study population (Table 1).No evidence of gender predominance was seen in our study.Of the Seventy patients 46 presented with symptoms in the right side i.e. $66 \%$ and 24 patients had disease in the left side i.e.34\% (Table 2). Out of 70, 40 patients with rotator cuff diseases presented with pain i.e. $57 \%$, $14 / 70$ reported of stiffness or reduced range of movement i.e. 20\%, 5/70 reported weakness of the shoulder joint i.e. $7 \%$, inability to raise the hand over the shoulders was observed in 5 patients i.e. $7 \%$ cases and combinations of more than one complaints was observed in 6 patients i.e. 9\% cases(Graph-1). Of the 70 patients $57(81 \%)$ abnormal supraspinatus tendons were noted. Of the subscapularis tendons, $18(25 \%)$ were pathological. Among the infraspinatus tendons, 13 (18\%) were abnormal. Abnormal bicipital tendons were seen in 55 $(78 \%)$. Of the tears minor tendons, 2 (3\%) were abnormal accounting for the least commonly affected rotator cuff tendons (Table-3). The most frequently affected tendon being supraspinatus 
and the least affected being teres minor. Of the pathologies of the supraspinatus tendon, tendinosis was seen in 10 patients (14\%) partial tear in $42(60 \%)$ and complete tear in $05(8 \%)$. Thus, partial tear and tendinopathy are the most commonly encountered abnormalities in the Supraspinatus tendons in this study population, accounting for $60 \%$ and $14 \%$ respectively (Table4). Among the abnormalities of subscapularis, tendinosis with no evidence of tear was noted in 3 (4\%) patients, tear noted in 15 (22\%), with partial in $14(20 \%)$ and complete in 1 (2\%) patient. Normal subscapularis tendon noted in $74 \%$ patients. Tendinosis was found in $1(1.4 \%)$ patient, partial tear in $10(14 \%)$ and complete tear of the infraspinatus tendon in $2(3 \%)$ patients. Rest of the patients had normal infraspinatus tendon 57 $(82 \%)$. Thus the frequent, abnormality in the infraspinatus in current study group was partial tear (Table-5). Associated abnormalities in bicipital tendons were noted in $55(78 \%)$ patients. The abnormalities seen in the tendon included tendinosis in $3(4 \%)$ patients, fluid around the tendon with no signal abnormality in the tendon / tenosynovitis in $49(70 \%)$ patients and tear of the tendon in 3 (4\%) patents (Table-6). Of the 70 patients there were 42 patients with partial tear of supraspinatus. Of these, the common type was the articular surface tear in $21(50 \%)$, followed by bursal tear in $11(26 \%)$ and the least common being the intra substance surface tear in 10 i.e. 24\% (Graph-2).

Table 1: patient's demographic value

\begin{tabular}{|l|c|c|}
\hline Gender & No. of patients & Percentage \\
\hline Male & 38 & $55 \%$ \\
\hline Female & 32 & $45 \%$ \\
\hline
\end{tabular}

Table 2: Hand dominance of rotator cuff pathologies

\begin{tabular}{|l|c|c|}
\hline Clinical symptoms in & No. of patients & Percentage \\
\hline Left hand & 24 & $34 \%$ \\
\hline Right hand & 46 & $66 \%$ \\
\hline
\end{tabular}

Graph 1- Clinical Presentation of Rotator Cuff Pathologies

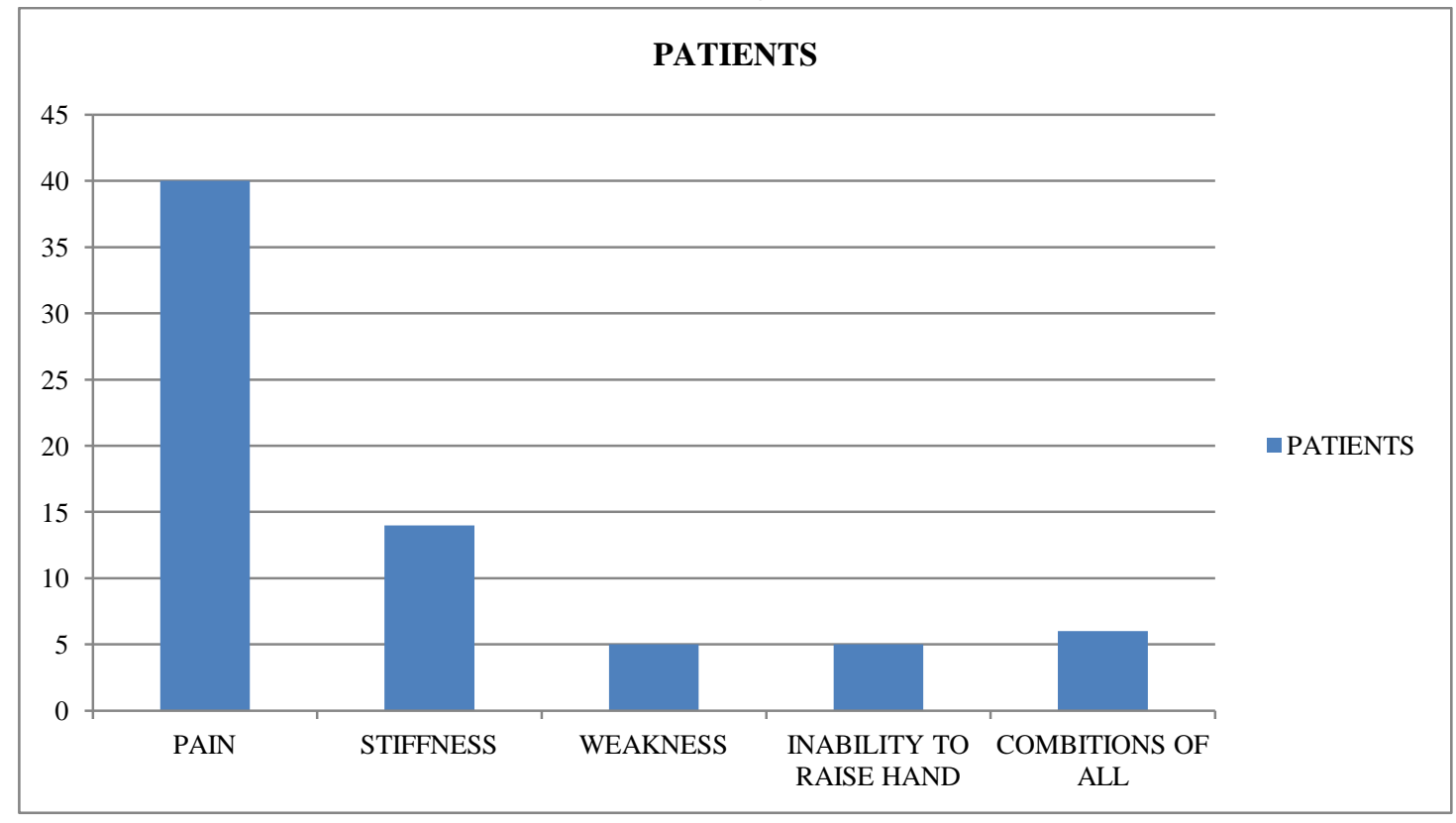

Table 3: Spectrum of Involvement of Rotator Cuff Tendons

\begin{tabular}{|l|c|c|}
\hline Involved Tendon & No of patients & Percentage \\
\hline Supraspinatus & 57 & $81 \%$ \\
\hline Infraspinatus & 13 & $18 \%$ \\
\hline Subscapularis & 18 & $25 \%$ \\
\hline Teres minor & 2 & $3 \%$ \\
\hline Biceps tendon & 55 & $78 \%$ \\
\hline
\end{tabular}


Table 4: Supraspinatus Tendon Pathology in Study Population

\begin{tabular}{|l|c|c|}
\hline Supraspinatus pathology & No. of patients & Percentage \\
\hline Normal & 13 & $18 \%$ \\
\hline Partial tear & 42 & $60 \%$ \\
\hline Complete tear & 05 & $8 \%$ \\
\hline Tendinosis & 10 & $14 \%$ \\
\hline Total patients & 70 & $100 \%$ \\
\hline
\end{tabular}

Table 5: Subscapularis and Infraspinatus Tendon Pathology in Study Population

\begin{tabular}{|l|c|c|c|c|}
\hline $\begin{array}{l}\text { Subscapularisand } \\
\text { Infraspinatus pathology }\end{array}$ & No. of patients & Percentage & No. of patients & Percentage \\
\hline Tendinosis & 3 & $4 \%$ & 1 & $2 \%$ \\
\hline Partial tear & 14 & $20 \%$ & 10 & $14 \%$ \\
\hline Complete tear & 1 & $2 \%$ & 2 & $3 \%$ \\
\hline Normal & 52 & $74 \%$ & 57 & $81 \%$ \\
\hline Total & 70 & $100 \%$ & 70 & $100 \%$ \\
\hline
\end{tabular}

Table: 6 Biceps Tendon Pathology

\begin{tabular}{|l|c|c|}
\hline Biceps tendon pathology & No. of patients & Percentage \\
\hline Normal & 15 & $22 \%$ \\
\hline Tenosynovitis & 49 & $70 \%$ \\
\hline Tear / Dislocation & 3 & $4 \%$ \\
\hline Tendinosis & 3 & $4 \%$ \\
\hline Total & 70 & $100 \%$ \\
\hline
\end{tabular}

Graph 2- Types of Partial Tear in Supraspinatus Tendon

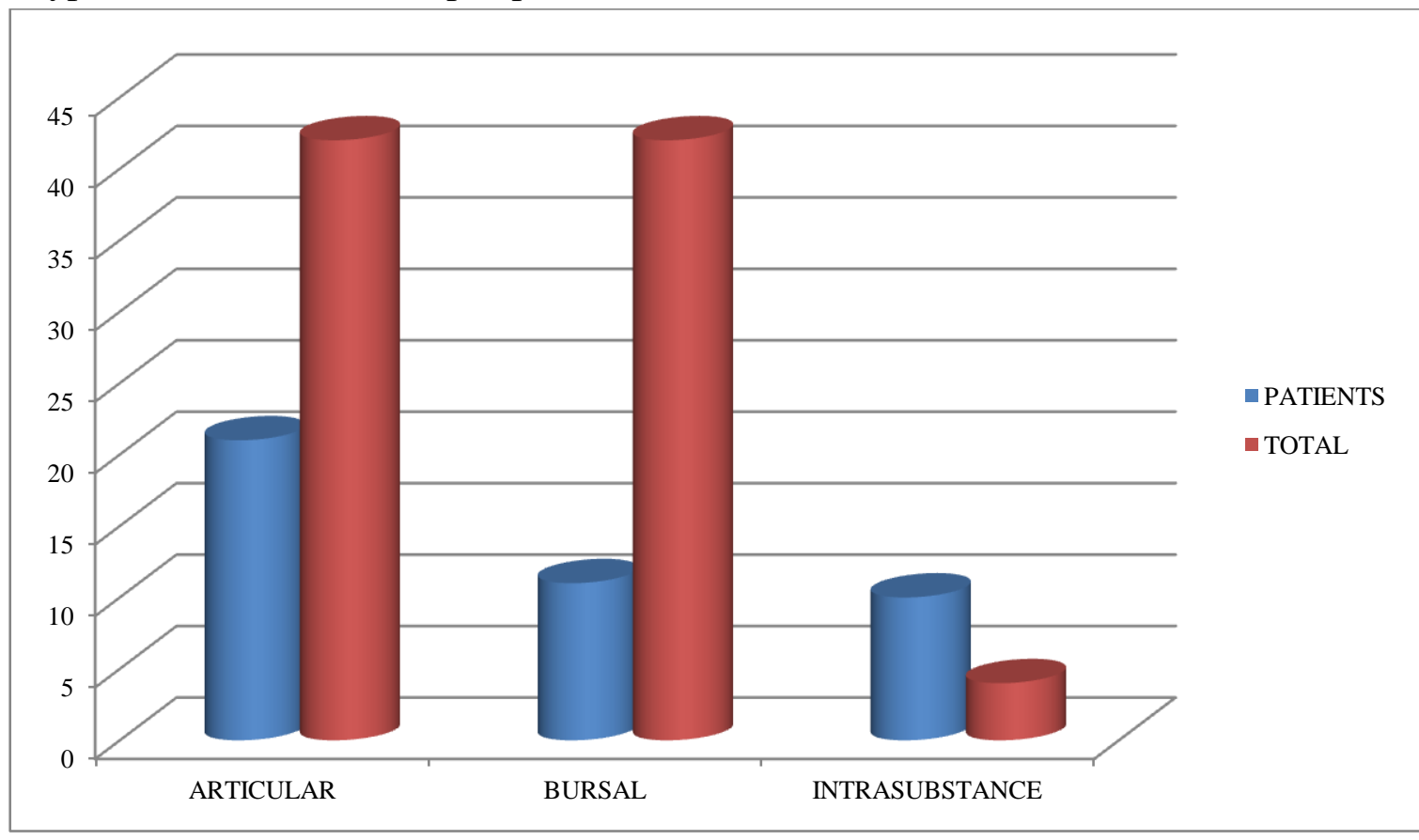

\section{Discussion}

Tendinopathy can be defined as an overuse condition of tendons that manifests itself as pain in and around tendons and occurs when the bodies regenerating capacity is minimized. ${ }^{10,11}$

Rotatorcuff tear differ in size and location. Tear less than $10 \mathrm{~mm}$ in size is considered as small tear, medium tears is $10-30 \mathrm{~mm}$ in size, and
$30 \mathrm{~mm}$ in size is considered as 'large' or 'massive' tear. $^{12-14}$ Sometimes rotator cuff lesions are asymptomatic especially in elderly patients while in some cases it is presented with different symptoms. In present study 70 patients aged above 18 years were selected $55 \%$ were males and $45 \%$ were females. However no evidence of gender predominance was seen in our study. 
Which was similar to those reported by Milogram et al. ${ }^{8}$

Of the Seventy patients 46 presented with symptoms in the right side i.e. $66 \%$ and 24 patients had disease in the left side i.e.34\%. Our study result is in favour of those reported by others. $^{8}$ Rotator cuff tears are often associated with various clinical presentations. In current study $57 \%$ patients complained of pain, $20 \%$ of stiffness or reduced movement. The most frequent complaint being pain among 40 subjects. Our results are in favour of those reported by other authors. ${ }^{15,16}$ In current study the most frequently affected tendon being supraspinatus and the least affected being teres minor, our results are in agreement with Walz DM et al. ${ }^{17}$ Partial tear and tendinopathy were the most commonly encountered abnormalities in the Supraspinatus tendons in this study population, accounting for $60 \%$ and $14 \%$ respectively.

Among the abnormalities of subscapularis, tendinosis with no evidence of tear was noted in $4 \%$ patients, tear noted in $22 \%$, with Codman had reported $3.5 \%$ involvement of the subscapularis tendon in his series of rotator cuff tears. ${ }^{6}$ Most common abnormality in the infraspinatus in current study group was partial tear. According to the literature available massive tear is more commonly seen in subscapularis tendon and is very painful in nature. ${ }^{18}$ Associated abnormalities in bicipital tendons were noted in $55(78 \%)$ patients. The common abnormal finding seen in relation to the biceps tendon in a rotator cuff disease in current study group was tenosynovitis our results are similar to those reported by Zanetti $M$ et al who also found bicipital tendinitis/ tenosynovitis to be commonly related to rotator cuff disease. ${ }^{19}$ Beall et al in their study concluded that tears of the long head of the biceps tendon have a statistically significant association with tears of the supraspinatus and subscapularis tendons. $^{20}$

\section{Conclusion}

Rotator cuff lesion is a complex disease which can have a huge impact on patient's life as in most of the cases it causes pain and restricted movement. Based on the result of our study pain was the most common clinical presentation noticed among people with RCT. Spectrum of involvement of rotator cuff tendon showed most commonly surpraspinatus tendon was involved. Partial tear was more common in surpraspinatus tendon.

\section{References}

1. Urwin M Symmons D Allison $\mathrm{T}$, et al Estimating the burden of musculoskeletal disorders in the community: the comparative prevalence of symptoms at different anatomical sites, and the relation to social deprivation. Annals of the rheumatic diseases. Nov 1998;57(11):649- 655

2. Shin KM Partial- thickness rotator cuff tears. The Korean journal of pain. Jun 2011;24(2):69- 73

3. Cadogan A, Laslett M, Hing W, McNair P, Coates M. A prospective study of shoulder pain in primary care: Prevalence of imaged pathology and response to guided diagnostic blocks. BMC Musculoskelet Disord. 2011;12:119.

4. Gartsman GM, Brinker MR, Khan M. Early effectiveness of arthroscopic repair for full-thickness tears of the rotator cuff. An outcome analysis. J Bone Joint Surg Am. 1998;80(1):33-40 [PubMed]

5. Ostor AJK, Richards CA, Prevost AT, Speed CA, Hazleman BL. Diagnosis and relation to general health of shoulder disorders presenting to primary care. Rheumatology. 2005;44:800-5

6. Codman EA Complete rupture of the supraspinatus tendon. Operative treatment with report of two successful cases. 1911. Journal of shoulder and elbow surgery / American Shoulder and Elbow 
Surgeons $\quad \ldots \quad$ [et $\quad$ al. $]. \quad$ Apr 2011;20(3):347- 349 [PubMed]

7. Jozsa L Kannus P Histopathological findings in spontaneous tendon ruptures Scand J Med Sci Sports. Apr 1997;7(2):113- 118

8. Milgrom C, Schaffler M, Gilbert S, van Holsbeeck M. Rotator-cuff changes in asymptomatic adults. The effect of age, hand dominance and gender. J Bone Joint Surg [Br] 1995; 77: 296-8

9. Bartolozzi A, Andreychik D, Ahmad S. Determinants of outcome in the treatment of rotator cuff disease. Clin OrthopRel Res. 1994;308:90-7

10. Andres BM Murrell GA Treatment of tendinopathy: what works, what does not, and what is on the horizon. Clinical orthopaedics and related research. Jul 2008;466(7):1539- 1554

11. Obaid H Connell D Cell therapy in tendon disorders: what is the current evidence? Am J Sports Med. Oct 2010;38 (10):2123- 2132

12. Bateman JE. The diagnosis and treatment of ruptures of the rotator cuff. SurgClin North Am.1963;43:1523-30

13. Gerber C, Fuchs B, Hodler J. The results of repair of massive tears of the rotator cuff. J Bone Joint Surg Am. 2000;82 (4):505-15

14. Snyder SJ. Evaluation and treatment of the rotator cuff. Orthop Clin North Am. 1993;24 (1):173-92

15. Jobe FW, Moynes DR. Delineation of diagnostic criteria and a rehabilitation program for rotator cuff injuries. Am J Sports Med 1982; 10: 336-9.

16. Safran O, Schroeder J, Bloom R, Weil Y, Milgrom C. Natural history of non operatively treated symptomatic rotator cuff tears in patients 60 years old or younger. Am J SPORTS MED. Apr 2011; 39:710-4.

17. Walz DM, Miller TT, Chen S, Hofman J. MR imaging of delamination tears of the rotator cuff tendons. Skeletal Radiol. 2007; 36:411-16

18. Pagnani MJ, Deng XH, Warren RF, Torzilli PA, O'Brien SJ. Role of the long head of the biceps brachii in glenohumeral stability: a biomechanical study in cadavera. J Shoulder Elbow Surg 1996; 5: 255-6.

19. Zanetti M, Weishaupt D, Gerber C, Hodler $\mathrm{J}$. Tendinopathy and rupture of the long head of the biceps brachii muscle: evaluation with MR arthrography. AJR Am J Roentgenol 1998; 170(6):1557-61

20. Beall DP, Williamson EE, Ly JQ, Adkins MC, Emery RL, Jones TP. Association of Biceps Tendon Tears with Rotator Cuff Abnormalities: Degree of Correlation with Tears of the Anterior and Superior Portions of the Rotator Cuff: AJR Am J Roentgenol 2003; 180(3):633-39. 